\title{
Non-coding RNAs: novel players in chromatin-regulation during viral latency Sebastian Eilebrecht ${ }^{1}$, Christian Schwartz ${ }^{2}$ and Olivier Rohr ${ }^{2}$
}

\begin{abstract}
Chromatin structure plays an essential role during gene expression regulation not only in the case of the host cellular genome, but also during the viral life cycle. Epigenetic chromatin marks thereby define, whether a gene promoter is accessible for the transcription machinery or whether a repressive heterochromatin state is established. The heterochromatin-mediated repression of lytic viral genes results in viral latency, enabling the virus to persist dormant without being recognized by the host immune system, but keeping the potential for reactivation. Arising new systems biology approaches are starting to uncover an unexpected multiplicity and variety of non-coding (nc)RNAs playing important roles during chromatin structure control, likely constituting a novel layer in epigenetic regulation. In this review we give an overview of chromatin-regulatory viral and host cellular ncRNAs and their links to viral latency.

Addresses

${ }^{1}$ Vaccine Research Institute, INSERM U955, 8 rue du Général Sarrail, 94010 Créteil, France

${ }^{2}$ Institut de Parasitologie et de Pathologie Tropicale, 3 rue Koeberlé, 67000 Strasbourg, France
\end{abstract}

Corresponding author: Eilebrecht, Sebastian

(sebastian.eilebrecht@inserm.fr, sebastian.eilebrecht@rub.de)

\begin{abstract}
Current Opinion in Virology 2013, 3:xx-yy
This review comes from a themed issue on Viral genomics

Edited by Arndt Benecke and Michael Katze
\end{abstract}

$1879-6257 / \$$ - see front matter, (C) 2013 Elsevier B.V. All rights reserved.

http://dx.doi.org/10.1016/j.coviro.2013.04.001

\section{Introduction}

The shift from lytic to latent infection represents an important viral mechanism to escape the host immune system. Viral latency is associated with the transcriptional repression of genes involved in lytic infection, resulting in a dormant viral genome, which remains competent for reactivation. Often this dormant state is maintained by the expression of few latency-associated viral gene products $[1,2]$.

During the last decades, chromatin structural dynamics have gained increasing attention during the establishment of both episomal [3] and proviral latency [4,5]. Upon initial infection, viral DNA - either episomal
DNA or integrated proviral DNA — is packed by host cellular chromatin. Epigenetic modifications, such as histone acetylation, histone methylation or DNA methylation alter this chromatin structure and thus determine the availability of gene promoters for the transcription machinery [6]. The chromatin state leading to viral latency is believed to depend on host cellular factors and, in the case of retroviruses, on the site of integration [7].

Recently, non-coding RNAs such as micro (mi)RNAs [8,9], long non-coding (lnc)RNAs [10-12] and natural antisense transcripts (NATs) [13,14] have emerged as being significantly involved in the epigenetic regulation of chromatin structure. Here we introduce the most important chromatin-modifying complexes involved in viral latency and give an overview of host cellular and viral ncRNAs impacting their activity, thus likely being important factors during latency establishment.

\section{Chromatin dynamics associated with viral latency}

Numerous mechanisms have been proposed to be involved in establishing and maintaining viral latency. These mechanisms depend on the virus type, the chromatin environment, transcriptional interference, the lack of cellular or viral activators or the presence of host repressors. Transcriptional repression that induces viral latency is commonly associated with the epigenetic silencing of viral promoters [15] (Figure 1). Here, we briefly present the currently known epigenetic mechanisms that are responsible for the establishment and persistence of episomal and proviral latency.

\section{Chromatin regulation during episomal latency}

An extensively studied example for episomal latency is established by the herpes virus family, comprising herpes simplex virus (HSV1). The epigenetic regulation of latent HSV1 gene expression relies on posttranslational histone modifications but not on DNA methylation [16-18]. Establishment of latency is associated with the recruitment of several proteins, including HDACs and polycomb-repressive complex 2 (PRC2) components, to lytic gene promoters $[16,18]$. Upon viral reactivation, HCF-1, a component of the SET1 and MLL1 HMT complexes, recruits LSD1 and induces H3K4 trimethylation and transcriptional activation of the HSV promoter [19-21].

\section{Chromatin regulation during proviral latency}

Proviral latency is established by the family of retroviruses, which includes HIV-1. Upon reverse 
2 Viral genomics

Figure 1

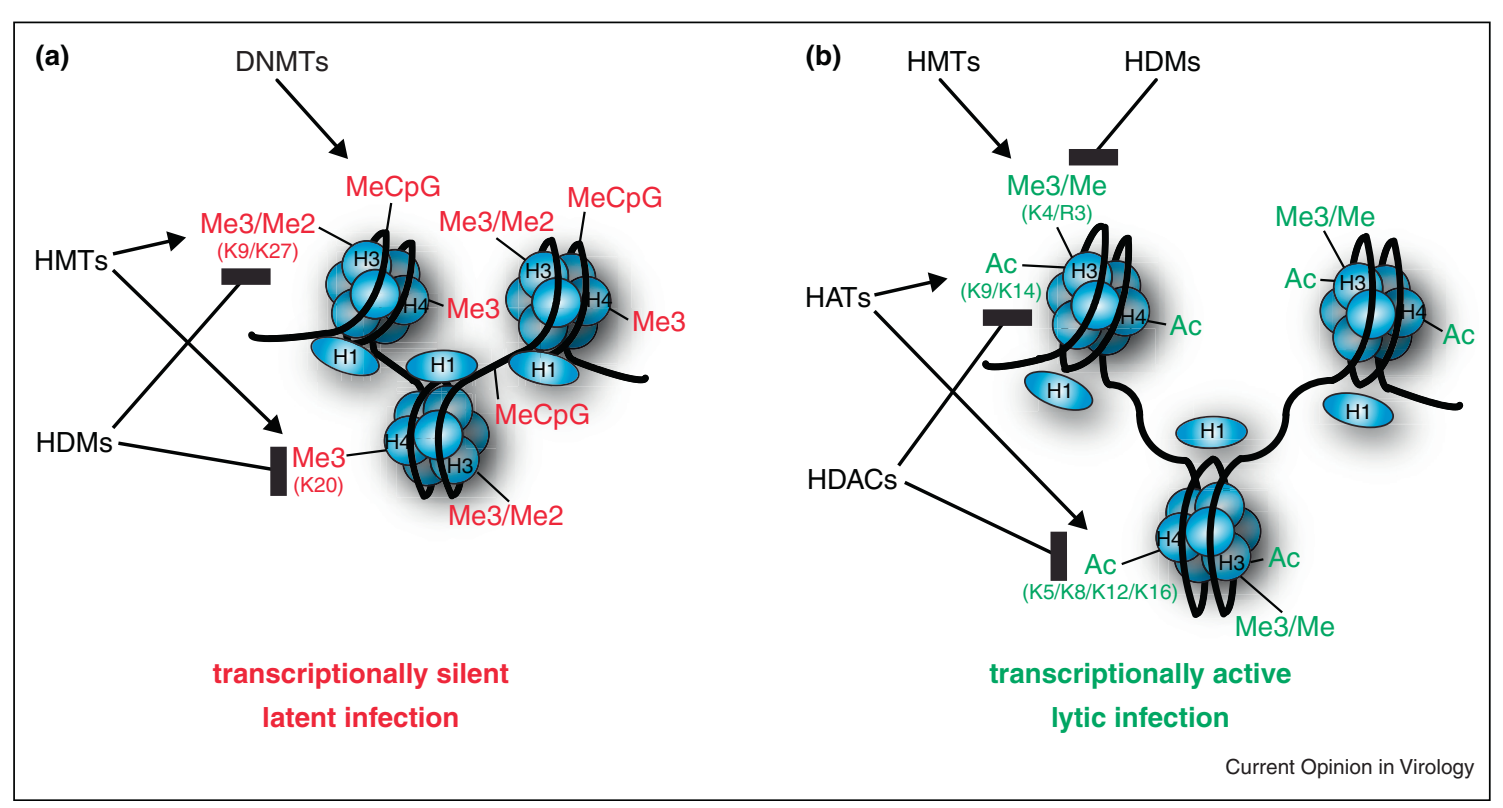

Chromatin structure and viral latency. (a) Schematic representation of transcription-repressive heterochromatin at lytic viral promoters, supporting the establishment of viral latency: the posttranslational dimethylation (Me2) or trimethylation (Me3) of histone H3 lysine residues 27 and 9 (H3K27/H3K9) and histone $\mathrm{H} 4$ lysine residue 20 (H4K20) as well as the direct methylation of $\mathrm{CpG}$ islands (MeCpG) within gene promoters are predominantly associated with transcriptional silencing. Host cellular histone methyltransferases (HMTs) and histone demethylases (HDMs) are responsible for the methylation and demethylation of histone tails, respectively, while DNA methyltransferases (DNMTs) catalyze the methylation of CpG islands. (b) Schematic view of actively transcribed euchromatin: the trimethylation (Me3) of histone $\mathrm{H} 3$ lysine residue 4 (H3K4) and the monomethylation (Me) of arginine residue $3(\mathrm{H} 3 \mathrm{R} 3)$ as well as the acetylation (Ac) of histone $\mathrm{H} 3$ lysine residues 9 and 14 (H3K9, H3K14) and histone $\mathrm{H} 4$ lysine residues $5,8,12$ and 16 (H4K5, H4K8, H4K12, H4K16) are predominantly associated with active transcription. Besides HMTs and HDMs, histone acetyltransferases (HATs) and histone deacetylases (HDACs) are involved in the setting and erasing of these chromatin marks, respectively. Also a decreased binding of the linker histone $\mathrm{H} 1$ is involved in chromatin remodeling.

transcription, the retroviral genome is integrated into the host cellular genome, where it either resides transcriptionally active or dormant, leading to virion production or latency, respectively. Epigenetic silencing of viral transcription constitutes the major mechanism involved in both establishing and maintaining latency and, in contrast to episomal latency, relies on both DNA methylation and histone modifications [5,22] (Figure 1). In microglial cells, the viral reservoirs in the CNS, we have shown that the cellular proteins CTIP2 and LSD1 synergistically repress HIV-1 transcription [23,24]. Indeed, CTIP2 recruits HDAC1, HDAC2 and SUV39h1, leading to H3K9 deacetylation and trimethylation, respectively [24]. Surprisingly, LSD1 recruits hSET1 and WDR5, two members of the human complex proteins associated with Set1 (hCOMPASS), to trimethylate H3K4 [23]. Association of both $\mathrm{H} 3 \mathrm{~K} 4 \mathrm{me} 3$ and $\mathrm{H} 3 \mathrm{~K} 9 \mathrm{me} 3$ epigenetic marks with LSD1 recruitment may thus constitute a new level of eukaryotic gene regulation. Such a gene repression linked to $\mathrm{H} 3 \mathrm{~K} 4 \mathrm{me} 3$ has been proposed to prevent the expression of cryptic promoters $[25,26]$. This is strengthened by the findings that HIV-1 preferentially integrates into active genes and therefore could be considered as a cryptic gene.
Interestingly and as described for HSV, a PRC2 complex is involved in epigenetic silencing of HIV-1 by trimethylation of H3K27 [27].

\section{Non-coding RNAs in chromatin regulation}

During the last years, an increasing number of ncRNAs has emerged being potently involved in chromatin structural dynamics, acting as recruiting factors, scaffolds or decoys for epigenetic chromatin-modifying enzymes [28]. While certain miRNAs recruit epigenetic regulators via sequence-specific interactions with their target genes, the regulatory mechanisms utilized by lncRNAs are classified into cis and trans (Figure 2) [28]. Here we focus on transacting host lncRNAs, viral lncRNAs including long antisense transcripts and viral miRNAs.

\section{Trans-acting long non-coding RNAs}

In contrast to miRNAs, lncRNAs predominantly exert their function via intramolecular secondary structure formation, enabling them to specifically bind cellular interaction partners. They can be classified according to their locus and orientation with respect to the surrounding protein-coding genes. 
Figure 2

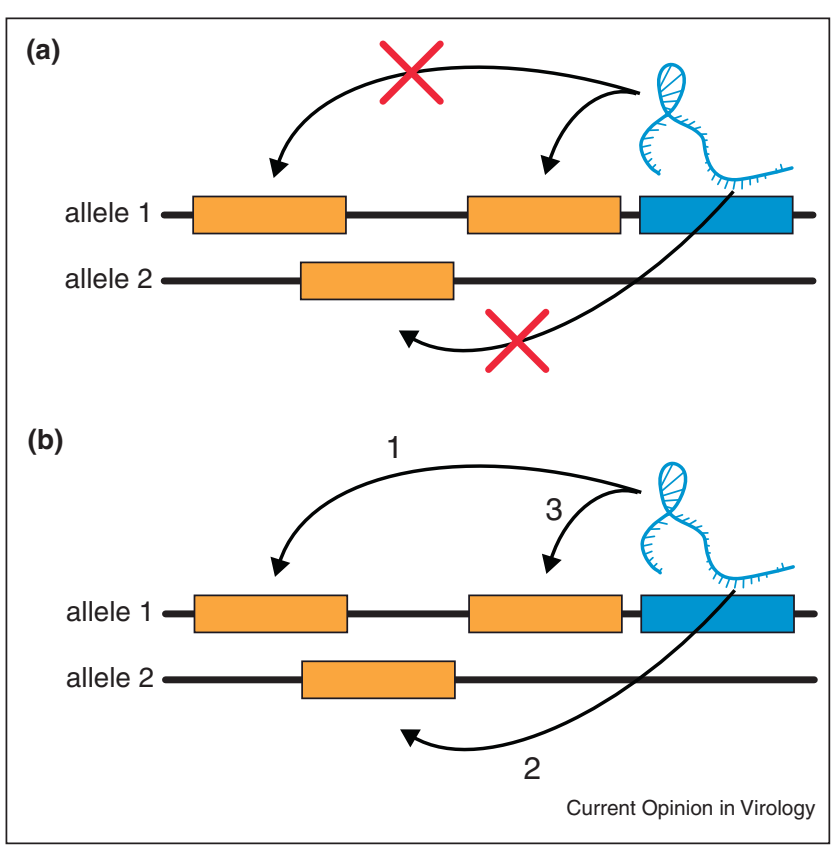

Cis-regulation versus trans-regulation. (a) In a cis-regulatory mechanism the expression of the ncRNA is directly correlated with the expression of a neighboring gene on the same allele (adapted from Guttman and Rinn [28]). (b) Trans-regulation is believed to be a more general mechanism, which can affect the expression of distant genes (1) or genes located on the other allele (2). Also the expression of neighboring genes can be affected (3), but such an effect here is indirect and involves mediating factors. Thus, apart from cis-regulatory host IncRNAs affecting chromatin structure directly at the site of retroviral integration and apart from viral IncRNAs, IncRNA candidates affecting chromatin structure during episomal and proviral latency are likely to act in trans.

A recently discovered prominent long intergenic (li)ncRNA is the HOX antisense intergenic RNA (HOTAIR), which is transcribed in antisense orientation from the HOXG locus [29]. HOTAIR interacts with PRC2 and mediates PRC2-catalyzed H3K27 methylation at the HOXD locus in trans. HOTAIR is constitutively overexpressed in breast cancer cells, thereby inducing a re-targeting of PRC2, leading to genome-wide altered gene expression $\left[30^{\circ}\right]$. RNA immunoprecipitationsequencing (RIP-seq) studies have revealed more than 9000 PRC2-interacting RNAs, including promoter-associated transcripts and lincRNAs transcribed from all over the genome, advancing the regulation of PRC2-mediated chromatin-remodeling to a large variety of ncRNAs $\left[31^{\bullet \bullet}\right.$. More recent studies have shown HOTAIR to act as a scaffold between PRC2 and the HDM LSD1, which is believed to coordinate $\mathrm{H} 3 \mathrm{~K} 27$ methylation and H3K4 demethylation to silence target genes [32 $2^{\bullet \bullet}$ (Figure 3a). Genome-wide studies have proven about $20 \%$ of all cellular lincRNAs to be associated with PRC2, while about $10 \%$ showed an interaction with CoREST, a compound of LSD1-containing repressor complexes [33]. Remarkably, $40 \%$ of the CoRESTassociated lincRNAs also associate with PRC2, indicating that in addition to HOTAIR, many lincRNAs may act as scaffold for chromatin-modifying activities. 74 lincRNAs physically interact with various chromatin-modifying enzymes, among them the HDMs Jarid1b and Jarid1c, HDAC1, PRC2, the HMTs Eset, Setd8 and Suv39h1 as well as the HAT TIP60/P400 [34 ${ }^{\bullet \bullet}$, many of which have been previously shown to be involved in HIV-1 silencing [5].

Apart from these host cellular lncRNA examples there is also a variety of viral lncRNAs, which are particularly expressed either during the latent or the lytic phase of infection. Among the latter ones, the Kaposi's sarcomaassociated herpesvirus (KSHV) encoded polyadenylated nuclear (PAN) RNA mediates infectious virion production [35]. It associates with the HDMs JMJD3 and UTX and with the HMT MLL2 to target these activities to the KHSV promoter, leading to increased H3K27 demethylation and H3K4 methylation and thus to transcription activation $\left[36^{\circ}\right]$ (Figure 3b). During HSV latency, only the latency-associated transcript (LAT) is expressed at high levels and promotes heterochromatin formation on lytic promoters in a mouse model [37]. However, this potential function of LAT appears to depend on the animal model used [16] and will need to be further investigated.

Besides the epigenetic modification of core histones also the competitive displacement of linker histones has been implicated in chromatin structural dynamics [38] (Figure 1). In recent studies we have identified the essential 7SK ncRNA as decoy for the histone H1 antagonist HMGA1 $\left[39^{\bullet}, 40\right]$ (Figure 3c). Apart from its function as a repressor of the positive transcription elongation factor $\mathrm{b}(\mathrm{P}-\mathrm{TEFb})$ [41], 7SK RNA regulates the expression of more than 1500 HMGA1 target genes. Since P-TEFb activity is also critical for efficient HIV-1 genome expression [42], the recent identification of 7SK complexes containing both HMGA1 and P-TEFb directly links chromatin-remodeling and transcription elongation control during HIV latency [43].

\section{Long antisense transcripts and cis regulation}

Unlike other lncRNAs, long antisense transcripts usually regulate their target genes by recruiting epigenetic effectors via a sequence-specific interaction with their complementary nascent sense mRNA in cis [13] (Figure 3d). For instance, the antisense ncRNA in the INK4 locus (ANRIL) overlaps with the locus, which encodes for the cyclin-dependent kinase inhibitors p15INK4b and p16INK4a and the p53 regulator ARF. ANRIL affects the expression of its target genes by two different mechanisms: it mediates p15INK4b repression by PRC2mediated heterochromatin formation and DNA methylation $\left[44^{\bullet \bullet}, 45\right]$ and it silences p16INK4a expression via 
4 Viral genomics

Figure 3

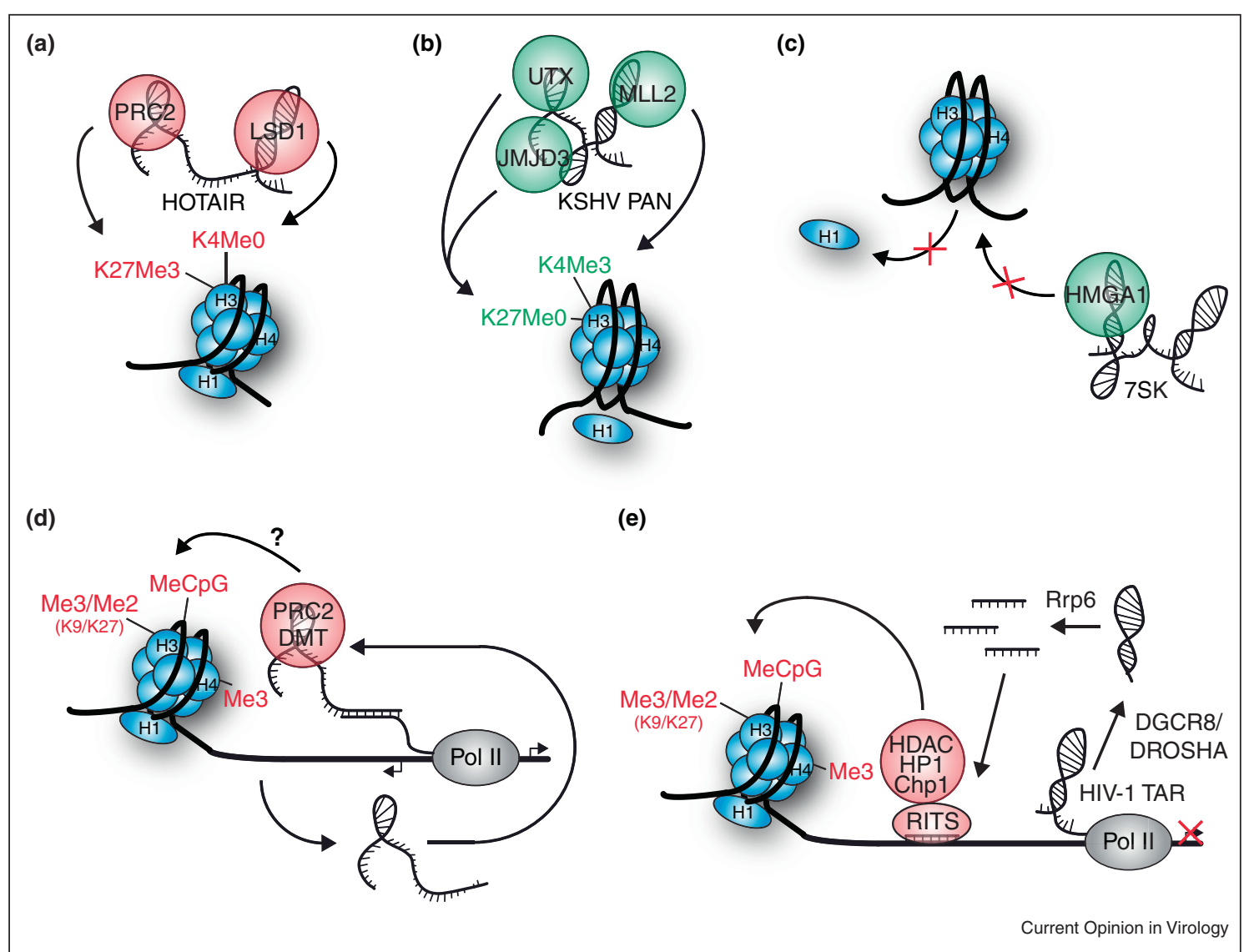

Non-coding RNAs during chromatin regulation. (a) The lincRNA HOTAIR acts as a scaffold for the HMT PRC2 and the HDM LSD1 in order to silence gene expression by the coordination of H3K27 trimethylation (H3K27Me3) and demethylation of H3K4 (H3K4Me0). (b) The KHSV-expressed PAN RNA activates viral gene expression by recruiting the HDMs UTX and JMJD3 and the HMT MLL2, resulting in H3K27 demethylation (H3K27Me0) and H3K4 trimethylation (H3K4Me3), respectively. (c) Cellular 7SK RNA acts as decoy for the histone H1 antagonist and chromatin master regulator HMGA1. (d) Long antisense transcripts, such as ANRIL, are involved in the recruitment of chromatin-modifying enzymes (PRC2, DNMTs?) to gene promoters by basepairing with their complementary sequence within the nascent mRNA, resulting in gene expression silencing. (e) HIV-1 TAR is processed by DGCR8, DROSHA and Rrp6 to miRNAs, which bind to their promoter proximal target sites and are believed to recruit RITS-associated chromatinmodifiers (HDACs, HP1, Chp1), which subsequently mediate HIV-1 silencing.

the recruitment of the HMT EZH2 and PRC1-compound CBX7 $\left[46^{\circ}\right]$.

Recent studies have demonstrated antisense transcription to occur also from the integrated HIV-1 genome [47]. A long antisense RNA transcribed from the $\mathrm{U} 3$ region of the $3^{\prime}$ LTR has been detected in infected cells [48*0]. Though the expression of this ncRNA affects gene expression in a repressive manner, until now cellular interaction partners remain unidentified, leaving the mechanism of gene repression elusive.

Also the target of the antisense transcript itself, the nascent viral mRNA may directly serve as a cis-regulatory element. We have recently shown the HIV-1 transactivating response (TAR) structure to bind the chromatin regulator HMGA1, resulting in diminished HIV gene expression [49]. In addition to the competitive inhibition of the interaction with Tat-activated P-TEFb, this HMGA1/TAR complex might also play important roles during chromatin remodeling at the viral promoter.

\section{Viral microRNAs}

The best characterized pathway of miRNA-mediated gene repression is posttranscriptional silencing via the RNA-induced silencing complex (RISC) [50]. Apart from that, more recent studies have revealed that such short transcripts can also target epigenetic heterochromatin formation [51]. By guiding the RNA-induced transcriptional silencing (RITS) complex to their complementary target sites, these RNAs recruit RITS-associating epigenetic silencers, such as the HMT Clr4 [52], the DMT Dnmt3a [53] or HDAC1 [54]. However, even though both viral and host cellular miRNAs have been shown to affect 
viral gene expression at the posttranscriptional level [55], there is only little known about miRNAs involved in the epigenetic regulation of viral target promoters.

In the case of HIV, the TAR element is a source for such miRNA species. It is recognized and cleaved by Dicer, producing miRNAs, which silence viral gene expression by facilitating the recruitment of HDAC1 to their promoter proximal target sites [54]. More recent studies have shown microprocessor to mediate premature termination of transcription upon TAR synthesis by recruiting the termination factors Setx and Xm2. The TAR element is subsequently cleaved by Drosha and processed by the exonuclease Rrp6 into miRNAs, which are believed to direct epigenetic silencing enzymes via the RITS pathway $\left[56^{\circ}\right]$ (Figure $3 \mathrm{e}$ ).

\section{Conclusions}

Viral latency constitutes a serious obstacle for the cure of viral infection. The antiretroviral treatment (ART) of HIV infected patients for instance is able to target actively virus-producing cells, but fails to attack latently infected cells, necessitating lifelong ART. A better comprehension of the mechanisms underlying establishment and persistence of HIV-1 latency will help to design therapies based on reactivation of reservoirs, which combined with an improved highly active ART could lead to a functional cure [57-60]. A repressive chromatin structure at the viral promoter has emerged as a critical prerequisite for latency establishment [15], making host cellular epigenetic regulators important players during the silencing of viral gene expression.

Though in most cases a wide range of cell types can be infected, often certain cell types are more prone to latency than others, such as CD34+ mononuclear hematopoietic progenitor cells in the case of cytomegalovirus (CMV) [61] or CD4+ T and monocyte-macrophage cells during HIV-1 infection [60,62], supporting the idea of cell-specific factors being major players during latency establishment.

Non-coding RNAs are gaining increasing attention as scaffolds and recruiting factors for chromatin regulators and thus may establish a novel, cell type specific layer during epigenetic regulation. Most of the known complexes involved in the establishment of heterochromatinassociated viral latency can be globally or specifically targeted by host cellular and/or viral ncRNAs to gene promoters. Notably, the expression of ncRNAs differs by far more than the expression of protein coding genes when comparing different cell types and tissues, making them promising candidate players during the chromatinmediated establishment of viral latency $\left[63,64^{\bullet \bullet}\right]$.

Deeper insights into ncRNA species specifically expressed in those cell types, which are prone to viral latency, will be required in order to identify RNAs participating in the epigenetic repression of viral genes. Such ncRNAs could represent novel therapeutic targets in order to eradicate latent viral reservoirs, which could in turn support ART to cure retroviral infection. Especially systems approaches applying recent powerful technologies such as next generation sequencing - as pioneered by Peng et al. [65] and Chang et al. [66 $6^{\circ}$ - RNA-seq, RIP-Seq or $5^{\prime} \mathrm{mC}$-Seq will substantially improve the detection of regulatory ncRNA networks during viral infection to advance our current knowledge about the establishment of viral latency and host-pathogen interactions in general [67].

\section{Conflict of interest statement}

The authors declare to have no competing interests.

\section{Acknowledgements}

S.E. is recipient of a postdoctoral fellowship of the Agence Nationale de recherches sur le SIDA et les hépatites virales (ANRS). O.R. and C.S. are supported by ANRS, Institut Universitaire de France (IUF) and Strasbourg university grants.

\section{References and recommended reading}

Papers of particular interest, published within the period of review, have been highlighted as:

- of special interest

- of outstanding interest

1. Divito $S$, Cherpes $T L$, Hendricks $R L:$ A triple entente: virus, neurons, and CD8+ T cells maintain HSV-1 latency. Immunol Res 2006, 36:119-126.

2. Ballestas ME, Kaye KM: The latency-associated nuclear antigen, a multifunctional protein central to Kaposi's sarcoma-associated herpesvirus latency. Future Microbiol 2011, 6:1399-1413.

3. Takacs M, Banati F, Koroknai A, Segesdi J, Salamon D, Wolf H, Niller $\mathrm{HH}$, Minarovits J: Epigenetic regulation of latent EpsteinBarr virus promoters. Biochim Biophys Acta 2010, 1799: 228-235.

4. Margolis DM: Histone deacetylase inhibitors and HIV latency. Curr Opin HIV AIDS 2011, 6:25-29.

5. Hakre S, Chavez L, Shirakawa K, Verdin E: Epigenetic regulation of HIV latency. Curr Opin HIV AIDS 2011, 6:19-24.

6. Benecke A: Genomic plasticity and information processing by transcription coregulators. ComPlexUs 2003, 1:65-76.

7. Marcello A: Latency: the hidden HIV-1 challenge. Retrovirology 2006, 3:7.

8. Van Wolfswinkel JC, Ketting RF: The role of small non-coding RNAs in genome stability and chromatin organization. $J$ Cell Sci 2010, 123:1825-1839.

9. Olovnikov I, Aravin AA, Fejes Toth K: Small RNA in the nucleus: the RNA-chromatin Ping-Pong. Curr Opin Genet Dev 2012, 22:164-171.

10. Mercer TR, Mattick JS: Structure and function of long noncoding RNAs in epigenetic regulation. Nat Struct Mol Biol 2013, 20:300-307.

11. Flynn RA, Chang HY: Active chromatin and noncoding RNAs: an intimate relationship. Curr Opin Genet Dev 2012, 22:172-178.

12. Lee JT: Epigenetic regulation by long noncoding RNAs. Science 2012, 338:1435-1439.

13. Magistri M, Faghihi MA, St Laurent G 3rd, Wahlestedt C: Regulation of chromatin structure by long noncoding RNAs: 
6 Viral genomics

focus on natural antisense transcripts. Trends Genet 2012, 28:389-396.

14. Malecova B, Morris KV: Transcriptional gene silencing through epigenetic changes mediated by non-coding RNAs. Curr Opin Mol Ther 2010, 12:214-222.

15. Knipe DM, Lieberman PM, Jung JU, McBride AA, Morris KV, Ott M, Margolis D, Nieto A, Nevels M, Parks RJ, Kristie TM: Snapshots: chromatin control of viral infection. Virology 2013, 435:141-156.

16. Bloom DC, Giordani NV, Kwiatkowski DL: Epigenetic regulation of latent HSV-1 gene expression. Biochim Biophys Acta 2010, 1799:246-256.

17. Minarovits $\mathrm{J}$ : Epigenotypes of latent herpesvirus genomes. Curr Top Microbiol Immunol 2006, 310:61-80.

18. Nevels M, Nitzsche A, Paulus C: How to control an infectious bead string: nucleosome-based regulation and targeting of herpesvirus chromatin. Rev Med Virol 2011, 21:154-180.

19. Huang J, Kent JR, Placek B, Whelan KA, Hollow CM, Zeng PY, Fraser NW, Berger SL: Trimethylation of histone H3 lysine 4 by Set1 in the lytic infection of human herpes simplex virus 1. J Virol 2006, 80:5740-5746.

20. Liang Y, Vogel JL, Narayanan A, Peng H, Kristie TM: Inhibition of the histone demethylase LSD1 blocks alpha-herpesvirus lytic replication and reactivation from latency. Nat Med 2009, 15:1312-1317.

21. Narayanan A, Ruyechan WT, Kristie TM: The coactivator host cell factor-1 mediates Set1 and MLL1 H3K4 trimethylation at herpesvirus immediate early promoters for initiation of infection. Proc Natl Acad Sci U S A 2007, 104:10835-10840.

22. Donahue DA, Wainberg MA: Cellular and molecular mechanisms involved in the establishment of HIV-1 latency. Retrovirology 2013, 10:11.

23. Le Douce V, Colin L, Redel L, Cherrier T, Herbein G, Aunis D, Rohr O, Van Lint C, Schwartz C: LSD1 cooperates with CTIP2 to promote HIV-1 transcriptional silencing. Nucleic Acids Res 2012, 40:1904-1915.

24. Marban C, Suzanne S, Dequiedt F, de Walque S, Redel L, Van Lint C, Aunis D, Rohr O: Recruitment of chromatin-modifying enzymes by CTIP2 promotes HIV-1 transcriptional silencing. $E M B O J$ J 2007, 26:412-423.

25. Pinskaya M, Gourvennec S, Morillon A: H3 lysine 4 di- and tri-methylation deposited by cryptic transcription attenuates promoter activation. EMBO J 2009, 28:1697-1707.

26. Pinskaya M, Morillon $\mathrm{A}$ : Histone $\mathrm{H} 3$ lysine 4 di-methylation: a novel mark for transcriptional fidelity? Epigenetics 2009, 4:302-306.

27. Friedman J, Cho WK, Chu CK, Keedy KS, Archin NM, Margolis DM, Karn J: Epigenetic silencing of HIV-1 by the histone H3 lysine 27 methyltransferase enhancer of zeste 2. J Virol 2011, 85:9078-9089.

28. Guttman M, Rinn JL: Modular regulatory principles of large noncoding RNAs. Nature 2012, 482:339-346.

29. Rinn JL, Kertesz M, Wang JK, Squazzo SL, Xu X, Brugmann SA, Goodnough LH, Helms JA, Farnham PJ, Segal E, Chang HY: Functional demarcation of active and silent chromatin domains in human HOX loci by noncoding RNAs. Cell 2007, 129:1311-1323.

30. Gupta RA, Shah N, Wang KC, Kim J, Horlings HM, Wong DJ,

- Tsai MC, Hung T, Argani P, Rinn JL, Wang Y et al:: Long noncoding RNA HOTAIR reprograms chromatin state to promote cancer metastasis. Nature 2010, 464:1071-1076.

This study demonstrated that HOTAIR is overexpressed in breast cancer, which results in genome-wide changes of PRC2-mediated H3K27 methylation. The resulting changes in gene expression lead to an increase of metastatic potential.

31. Zhao J, Ohsumi TK, Kung JT, Ogawa Y, Grau DJ, Sarma K,

-• Song JJ, Kingston RE, Borowsky M, Lee JT: Genome-wide identification of polycomb-associated RNAs by RIP-seq. Mol Cell 2010, 40:939-953.

Zhao et al. have developed a RNA immunoprecipitation method to globally identify more than 9000 PRC2-associated RNAs in embryonic stem cells.
32. Tsai MC, Manor O, Wan Y, Mosammaparast N, Wang JK, Lan F

-• Shi Y, Segal E, Chang HY: Long noncoding RNA as modular scaffold of histone modification complexes. Science 2010, 329:689-693.

Tsai et al. showed that HOTAIR links PRC2 and LSD1 chromatin modifying activities. They demonstrated a genome-wide HOTAIR-mediated coordination of PRC2-mediated H3K27 methylation and LSD1-mediated H3K4 demethylation, resulting in transcriptional silencing.

33. Khalil AM, Guttman M, Huarte M, Garber M, Raj A, Rivea Morales D, Thomas K, Presser A, Bernstein BE, van Oudenaarden $A$, Regev $A$ et al.: Many human large intergenic noncoding RNAs associate with chromatin-modifying complexes and affect gene expression. Proc Natl Acad Sci U S A 2009, 106:11667-11672.

34. Guttman M, Donaghey J, Carey BW, Garber M, Grenier JK,

- Munson G, Young G, Lucas AB, Ach R, Bruhn L, Yang X et al.: LincRNAs act in the circuitry controlling pluripotency and differentiation. Nature 2011, 477:295-300.

This study functionally characterized lincRNAs expressed in mouse embryonic stem (ES) cells. Guttman et al. identified several lincRNAs associating with multiple chromatin-modifying enzymes and that way affecting gene expression patterns, which are important for ES cell state.

35. Borah S, Darricarrere N, Darnell A, Myoung J, Steitz JA: A viral nuclear noncoding RNA binds re-localized poly(A) binding protein and is required for late KSHV gene expression. PLOS Pathog 2011, 7:e1002300.

36. Rossetto CC, Pari G: KSHV PAN RNA associates with - demethylases UTX and JMJD3 to activate lytic replication through a physical interaction with the virus genome. PLOS Pathog 2012, 8:e1002680.

This study demonstrated a role of KSHV PAN RNA in activating the repressed KSHV genome by recruiting the HDMs UTX and JMJD3 as well as the HMT MLL2 to the viral promoter, resulting in a decrease of the repressive H3K27 chromatin mark.

37. Cliffe AR, Garber DA, Knipe DM: Transcription of the herpes simplex virus latency-associated transcript promotes the formation of facultative heterochromatin on lytic promoters. $J$ Virol 2009, 83:8182-8190.

38. Li G, Reinberg D: Chromatin higher-order structures and gene regulation. Curr Opin Genet Dev 2011, 21:175-186.

39. Eilebrecht S, Brysbaert G, Wegert T, Urlaub H, Benecke BJ,

- Benecke A: 7SK small nuclear RNA directly affects HMGA1 function in transcription regulation. Nucleic Acids Res 2011 39:2057-2072.

This study identified 7SK RNA as a negative regulator of the chromatin master regulator and histone $\mathrm{H} 1$ antagonist HMGA1.

40. Eilebrecht S, Becavin C, Leger H, Benecke BJ, Benecke A: HMGA1-dependent and independent 7SK RNA gene regulatory activity. RNA Biol 2011, 8:143-157.

41. Zhou $\mathrm{Q}, \mathrm{Li} \mathrm{T}$, Price $\mathrm{DH}$ : RNA polymerase II elongation control. Annu Rev Biochem 2012, 81:119-143.

42. Ott M, Geyer M, Zhou Q: The control of HIV transcription: keeping RNA polymerase II on track. Cell Host Microbe 2011, 10:426-435.

43. Eilebrecht S, Benecke BJ, Benecke A: 7SK snRNA-mediated, gene-specific cooperativity of HMGA1 and P-TEFb. RNA Biol 2011, 8:1084-1093.

44. Kotake $Y$, Nakagawa T, Kitagawa K, Suzuki S, Liu N, Kitagawa M,

-1 Xiong Y: Long non-coding RNA ANRIL is required for the PRC2 recruitment to and silencing of p15(INK4b) tumor suppressor gene. Oncogene 2011, 30:1956-1962.

Together with Yap et al. this study identified the function of the antisense transcript ANRIL. Kotake et al. showed that ANRIL silences the expression of the tumor suppressor $\mathrm{p} 15 / \mathrm{INK} 4 \mathrm{~b}$ by recruiting the HMT complex PRC2, leading to H3K27 trimethylation at the P15/INK4b locus.

45. Yu W, Gius D, Onyango P, Muldoon-Jacobs K, Karp J, Feinberg AP, Cui $\mathrm{H}$ : Epigenetic silencing of tumour suppressor gene $\mathrm{p} 15$ by its antisense RNA. Nature 2008, 451:202-206.

46. Yap KL, Li S, Munoz-Cabello AM, Raguz S, Zeng L, Mujtaba S,

- Gil J, Walsh MJ, Zhou MM: Molecular interplay of the noncoding RNA ANRIL and methylated histone H3 lysine 27 by polycomb 
CBX7 in transcriptional silencing of INK4a. Mol Cell 2010, 38:662-674.

This study identified ANRIL-mediated epigenetic silencing of the tumor suppressor $\mathrm{p} 16 / \mathrm{INK} 4 \mathrm{a}$ locus by recruiting chromobox 7 and polycomb repressive complex 1 .

47. Landry S, Halin M, Lefort S, Audet B, Vaquero C, Mesnard JM, Barbeau B: Detection, characterization and regulation of antisense transcripts in HIV-1. Retrovirology 2007, 4:71.

48. Kobayashi-Ishihara M, Yamagishi M, Hara T, Matsuda Y,

- Takahashi R, Miyake A, Nakano K, Yamochi T, Ishida T, Watanabe T: HIV-1-encoded antisense RNA suppresses viral replication for a prolonged period. Retrovirology 2012, 9:38.

This study characterized a major occurring antisense transcript arising from HIV provirus and identified this transcript to play a role during viral replication.

49. Eilebrecht S, Wilhelm E, Benecke BJ, Bell B, Benecke AG: HMGA1 directly interacts with TAR to modulate basal and Tatdependent HIV transcription. RNA Biol 2013, 10:1-9.

50. Hammond SM: Dicing and slicing: the core machinery of the RNA interference pathway. FEBS Lett 2005, 579:5822-5829.

51. Lejeune E, Bayne EH, Allshire RC: On the connection between RNAi and heterochromatin at centromeres. Cold Spring Harb Symp Quant Biol 2010, 75:275-283.

52. Noma K, Sugiyama T, Cam H, Verdel A, Zofall M, Jia S, Moazed D, Grewal SI: RITS acts in cis to promote RNA interferencemediated transcriptional and post-transcriptional silencing. Nat Genet 2004, 36:1174-1180.

53. Weinberg MS, Villeneuve LM, Ehsani A, Amarzguioui M, Aagaard L, Chen ZX, Riggs AD, Rossi JJ, Morris KV: The antisense strand of small interfering RNAs directs histone methylation and transcriptional gene silencing in human cells. RNA 2006, 12:256-262.

54. Klase Z, Kale P, Winograd R, Gupta MV, Heydarian M, Berro R, McCaffrey T, Kashanchi F: HIV-1 TAR element is processed by dicer to yield a viral micro-RNA involved in chromatin remodeling of the viral LTR. BMC Mol Biol 2007, 8:63.

55. Cullen BR: Viruses and microRNAs: Riscy interactions with serious consequences. Genes Dev 2011, 25:1881-1894.

56. Wagschal A, Rousset E, Basavarajaiah P, Contreras X, Harwig A

- Laurent-Chabalier S, Nakamura M, Chen X, Zhang K, Meziane O, Boyer F et al.: Microprocessor, Setx, Xrn2, and Rrp6 co-operate to induce premature termination of transcription by RNAPII. Cell 2012, 150:1147-1157.

Wagschal et al. characterized the cellular factors involved in the premature termination of HIV transcription, the cleavage of HIV-1 TAR and the subsequent processing to viral miRNAs, which are thought to be subsequently involved in chromatin remodeling at the HIV promoter (as shown by Klase et al. [54]).

57. Bouchat S, Gatot JS, Kabeya K, Cardona C, Colin L, Herbein G, De Wit S, Clumeck N, Lambotte O, Rouzioux C, Rohr O et al:: Histone methyltransferase inhibitors induce HIV-1 recovery in resting
CD4(+) T cells from HIV-1-infected HAART-treated patients. AIDS 2012, 26:1473-1482.

58. Colin L, Van Lint C: Molecular control of HIV-1 postintegration latency: implications for the development of new therapeutic strategies. Retrovirology 2009, 6:111.

59. Le Douce V, Janossy A, Hallay H, Ali S, Riclet R, Rohr O, Schwartz C: Achieving a cure for HIV infection: do we have reasons to be optimistic? J Antimicrob Chemother 2012, 67:1063-1074.

60. Redel L, Le Douce V, Cherrier T, Marban C, Janossy A, Aunis D, Van Lint C, Rohr O, Schwartz C: HIV-1 regulation of latency in the monocyte-macrophage lineage and in CD4+ T lymphocytes. $J$ Leukoc Biol 2010, 87:575-588.

61. Reeves MB, Lehner PJ, Sissons JG, Sinclair JH: An in vitro model for the regulation of human cytomegalovirus latency and reactivation in dendritic cells by chromatin remodelling. J Gen Virol 2005, 86:2949-2954

62. Le Douce V, Herbein G, Rohr O, Schwartz C: Molecular mechanisms of HIV-1 persistence in the monocytemacrophage lineage. Retrovirology 2010, 7:32.

63. Cabili MN, Trapnell C, Goff L, Koziol M, Tazon-Vega B, Regev A, Rinn JL: Integrative annotation of human large intergenic noncoding RNAs reveals global properties and specific subclasses. Genes Dev 2011, 25:1915-1927.

64. Guttman M, Garber M, Levin JZ, Donaghey J, Robinson J

-. Adiconis X, Fan L, Koziol MJ, Gnirke A, Nusbaum C, Rinn JL et al.: $\mathrm{Ab}$ initio reconstruction of cell type-specific transcriptomes in mouse reveals the conserved multi-exonic structure of lincRNAs. Nat Biotechnol 2010, 28:503-510.

In this study a novel technology, based only on RNA-seq reads and the genome sequence, was applied to determine the cellular transcriptome. Different cell types from different tissues were compared and despite differentially expressed protein coding genes, strong differences in the expression of known and novel ncRNAs were detected.

65. Peng X, Gralinski L, Armour CD, Ferris MT, Thomas MJ, Proll S, Bradel-Tretheway BG, Korth MJ, Castle JC, Biery MC, Bouzek HK et al.: Unique signatures of long noncoding RNA expression in response to virus infection and altered innate immune signaling. MBio 2010, 1:5.

66. Chang ST, Sova P, Peng X, Weiss J, Law GL, Palermo RE,

- $\quad$ Katze MG: Next-generation sequencing reveals HIV-1mediated suppression of $T$ cell activation and RNA processing and regulation of noncoding RNA expression in a CD4+ T cell line. MBio 2011, 2:5

Chang et al. applied next generation sequencing technology to identify cellular and viral transcriptome changes upon HIV-1 infection in CD4+ T cells. Besides differentially expressed host and viral mRNAs, also the expression of ncRNAs were shown to be affected, including miRNAs, snoRNAs and antisense transcripts.

67. Benecke AG: Critical dynamics in host-pathogen systems. Curr Top Microbiol Immunol 2013, 363:235-259. 